\title{
EL DERECHO DEL MENOR A SER OÍDO Y A QUE SU OPINIÓN SEA TENIDA EN CUENTA
}

\author{
RONCESVALLES BARBER CÁRCAMO \\ CATEDRÁTICA DE DERECHO CiVIL \\ UNIVERSIDAD DE LA RIOJA \\ roncesvalles.barber@unirioja.es
}

SUMARIO: I. JUSTIFICACIÓN. II. REFLEJO NORMATIVO DEL DERECHO DEL MENOR A SER OÍDO. III. PRESUPUESTOS PARA EL EJERCICIO DEL DERECHO A SER OÍDO: EL DOBLE TEST DE CONVENIENCIA Y MADUREZ. IV. MODO DE EJERCICIO DEL DERECHO DE AUDIENCIA. V. EFICACIA DEL DERECHO DE AUDIENCIA DEL MENOR: V.1. SANCIÓN A LA INOBSERVANCIA DEL DERECHO DE AUDIENCIA. V.2. LA OPINIÓN DEL MENOR Y LA DETERMINACIÓN DE SU INTERÉS. VI. CONCLUSIONES.

RESUMEN: Este trabajo aborda el análisis de uno de los derechos medulares en la CDN de la ONU de 1989, el derecho del niño a ser oído y a que su opinión sea tenida en cuenta, recogido en su art. 12, que ha propiciado numerosas reformas legislativas y determinado cambios sustanciales en la aplicación del Derecho por los Tribunales, tanto a nivel internacional como nacional. En cuanto sirve a la identificación del interés superior del menor desde la perspectiva del más pleno ejercicio de sus derechos fundamentales, resulta revestido de un carácter rector o guía de todos los demás, al partir de la premisa de la capacidad del niño de formar su juicio y crearse sus propias opiniones sobre las realidades que le rodean. Por ello su análisis se revela especialmente fructífero e ilustrativo sobre el papel que la Declaración de los Derechos del Niño ha desempeñado en la evolución del Derecho en los últimos treinta años.

PALABRAS ClAVE: menores, audiencia, interés del menor.

\section{THE CHILD'S RIGHT TO BE HEARD AND TO HAVE THEIR OPINION TAKEN INTO ACCOUNT}

ABSTRACT: This work includes the analysis of one of the core rights in the UN CRC of 1989, the right of the child to express their views freely and being given due weight, as reflected in its art. 12, which has led to numerous legislative reforms and determined substantial changes in the application of the Law by the Courts, both internationally and nationally. As it serves to identify the best interests of the child from the perspective of the fullest exercise of their fundamental rights, this right inolves guiding character of all others, based on the premise of the child's ability to form his or her own judgment and create their own opinions about matters that affect them. Therefore, his analysis is especially fruitful and illustrative of the role that the Declaration of the Rights of the Child has played in the evolution of law in the last thirty years.

KEYWORDS: Minors, right to be heard, child's best interest. 


\section{Justificación}

La celebración de una efeméride tan relevante como el transcurso de treinta años desde la adopción por la Asamblea General de las Naciones Unidas de la Convención de los Derechos del Niño en 1989 ofrece un oportuno pretexto para reflexionar sobre el importante papel que la aplicación y el desarrollo de tales derechos ha jugado en la evolución reciente de las normas de Derecho internacional y nacional. Este trabajo aborda el análisis de uno de los derechos medulares en tal Convención, el derecho del niño a ser oído y a que su opinión sea tenida en cuenta, recogido en su art. 12, que ha propiciado numerosas reformas legislativas y determinado cambios sustanciales en la aplicación del Derecho por los Tribunales, tanto a nivel internacional como nacional. En cuanto sirve a la identificación del interés superior del menor desde la perspectiva del más pleno ejercicio de sus derechos fundamentales, resulta revestido de un carácter rector o guía de todos los demás, al partir de la premisa de la capacidad del niño de formar su juicio y crearse sus propias opiniones sobre las realidades que le rodean. Por ello su análisis se revela especialmente fructífero e ilustrativo de la incidencia de toda la Declaración de los Derechos del Niño.

En estas páginas se da cuenta al lector de cómo las fuentes legales españolas han recogido el derecho del menor a ser oído, así como cuál es la interpretación jurisprudencial vigente sobre las consecuencias que su reconocimiento comporta. Se emplea en ellas de forma indistinta las palabras niño, conforme a la terminología de la ONU, y menor, preferida por el legislador español. Por otra parte, aunque como observa atinadamente el Comité de los Derechos del Niño de la ONU en su Observación General número 12, dedicada a este derecho de audiencia, la CDN lo predica tanto de los niños como colectivo, como de cada uno de ellos. Centraré mi exposición en esta segunda aproximación, más propia del Derecho civil.

\section{Reflejo normativo del derecho del menor a ser oído}

El tratamiento jurídico actual de los menores, a nivel internacional y nacional, se sustenta sobre tres pilares básicos: el reconocimiento del incremento de su capacidad de ejercicio (o capacidad de obrar, en terminología y categoría empleada tradicionalmente), la necesaria fundamentación de las decisiones sobre los menores en su interés superior, y el derecho a ser oídos antes de adoptarse, en cualquier ámbito, una decisión que les afecte, como necesaria consecuencia de la primera y criterio para determinar el segundo.

La primera formulación normativa de este derecho de audiencia del menor se recoge en Convenios Internacionales. Aunque podamos remontarnos a otros anteriores, desde los años 30, tomaremos como punto de partida para este análisis la Convención sobre los Derechos del Niño (en adelante, CDN), adoptada por la Asamblea General de las Naciones Unidas por la Resolución 44/25, de 20 de noviembre de 19891. Su artículo 12 formula el derecho del niño a expresar su opinión y a que se tenga en cuenta con el siguiente texto:

\footnotetext{
${ }^{1}$ La CDN entró en vigor menos de un año después de su adopción, el 2 de septiembre de 1990.
} 
1. Los Estados Partes garantizarán al niño que esté en condiciones de formarse un juicio propio el derecho de expresar su opinión libremente en todos los asuntos que afectan al niño, teniéndose debidamente en cuenta las opiniones del niño, en función de la edad y madurez del niño.

2. Con tal fin, se dará en particular al niño oportunidad de ser escuchado, en todo procedimiento judicial o administrativo que afecte al niño, ya sea directamente o por medio de un representante o de un órgano apropiado, en consonancia con las normas de procedimiento de la ley nacional.

Pocos años después, el derecho de audiencia se recoge en el apartado 15 de la Carta Europea de Derechos del Niño, aprobada por el Parlamento Europeo el 8 de Julio de 1992², con el siguiente tenor literal:

15. Toda decisión familiar, administrativa o judicial, en lo que se refiere al niño, deberá tener por objeto prioritario la defensa y salvaguardia de sus intereses. A tales efectos, y siempre que ello no implique riesgo o perjuicio alguno para el niño, éste deberá ser oído desde el momento en que su madurez y edad lo permitan en todas las decisiones que le afecten. Con objeto de ayudar a tomar una decisión a las personas competentes, el niño deberá ser oído, especialmente en todos aquellos procedimientos y decisiones que impliquen la modificación del ejercicio de la patria potestad, la determinación de la guardia y custodia, la designación de su tutor legal, su entrega en adopción o su eventual colocación en una institución familiar, educativa o con fines de reinserción social. A este respecto, en la totalidad de los procedimientos deberá ser parte obligatoriamente el ministerio fiscal o su equivalente, cuya función primordial será la salvaguardia de los derechos e intereses del niño.

Adviértase que esta declaración tiene una redacción más detallada: además de referir el derecho tanto al ámbito público como al privado o familiar, insiste en que tanto la audiencia como su toma en consideración dependen de la edad y madurez del niño, así como en su función instrumental, en cuanto dirigida a identificar su interés. Asimismo, introduce algunas precisiones interesantes: el riesgo o el peligro del niño pueden justificar la exclusión de su práctica, y una enumeración, aun meramente ejemplificativa, de los procesos en que debe tener lugar.

Luego, la Carta de los Derechos fundamentales de la Unión Europea ${ }^{3}$ se refiere en su art. 24 a los derechos de los menores: pese a su brevedad, incluye el derecho a expresar libremente su opinión y a que ésta sea tenida en cuenta, además de subrayar el interés superior del menor ${ }^{4}$.

2 DOCE no C 241, de 21 de septiembre de 1992.

${ }^{3}$ En vigor desde el 1 de diciembre de 2009, junto con el Tratado de Lisboa.

${ }^{4}$ Carta de los Derechos Fundamentales de la UE: art. 24. Derechos del menor.

1. Los menores tienen derecho a la protección y a los cuidados necesarios para su bienestar. Podrán expresar su opinión libremente. Ésta será tenida en cuenta en relación con los asuntos que les afecten, en función de su edad y madurez. 
Posteriormente, España ha ratificado el Convenio Europeo sobre el ejercicio de los derechos de los niños ${ }^{5}$, cuyos arts. 3 y 6 recogen respectivamente la audiencia del menor como derecho de éste y como obligación del juez, así como sus implicaciones ${ }^{6}$.

Puede advertirse de la mera lectura de estos textos internacionales la complejidad del derecho abordado. En todos ellos se predica de los menores con discernimiento suficiente; se contempla como un derecho no meramente formal, sino dirigido a la intervención del menor en el proceso de toma de decisiones sobre su persona, para la mejor determinación de su interés superior, y cuyo ejercicio, con las cautelas que sean precisas, demanda la aportación previa al menor de la información suficiente.

En el Derecho español, la audiencia de los hijos menores, en las medidas a adoptar tras la crisis matrimonial de sus padres ("si tuvieran suficiente juicio y siempre a los mayores de doce años"), aparece en preceptos dispersos tras las reformas del Código civil de 1981. Desde entonces ha experimentado un progresivo desarrollo, consecuencia de una sensibilización social y jurídica en la que los textos internacionales transcritos han jugado un importante papel. Y la exigencia de la audiencia del menor en todas las decisiones que le atañen ha ido en nuestro Derecho de la mano de la recepción del interés del menor.

La L.0. 1/1996, de 15 de enero, de Protección del Menor, supuso la concreción en nuestro ordenamiento del espíritu y las medidas concretas de la CDN y formuló en nuestro Derecho con carácter general por primera vez el derecho del niño a ser oído en cualquier ámbito en que vaya a tomarse una decisión que le afecte (art. 9). La inicial formulación de este derecho, con una importante repercusión legislativa (civil, penal, procedimental), se ha completado y desarrollado sustancialmente tras la reforma de esta Ley por la LO 8/2015, de 22 de julio, de modificación del sistema de protección a la infancia y la adolescencia. Reforma que trae causa significativamente de los trabajos alumbrados por el Comité de los

2. En todos los actos relativos a los menores llevados a cabo por autoridades públicas o instituciones privadas, el interés superior del menor constituirá una consideración primordial.

${ }^{5}$ Instrumento de Ratificación del Convenio Europeo sobre el Ejercicio de los Derechos de los Niños, hecho en Estrasburgo el 25 de enero de 1996, BOE no 45, de 21 de febrero de 2015.

${ }^{6}$ Convenio Europeo sobre el Ejercicio de los Derechos de los Niños. Artículo 3. Derecho a ser informado y a expresar su opinión en los procedimientos.

Cuando según el derecho interno se considere que un niño tiene el suficiente discernimiento se le reconocerán, en los procedimientos que le afecten ante una autoridad judicial, los siguientes derechos cuyo ejercicio podrá exigir por sí mismo:

a. recibir toda la información pertinente;

b. ser consultado y expresar su opinión;

c. ser informado de las posibles consecuencias de actuar conforme a esa opinión y de las posibles consecuencias de cualquier resolución.

Artículo 6. Proceso de decisión.

En los procedimientos que afecten a un niño, la autoridad judicial, antes de tomar cualquier decisión, deberá:

a. examinar si dispone de información suficiente con el fin de tomar una decisión en el interés superior de aquél y, en su caso, recabar información complementaria, en particular de los titulares de las responsabilidades parentales;

b. cuando según el derecho interno se considere que el niño posee discernimiento suficiente:

- asegurarse de que el niño ha recibido toda la información pertinente;

- consultar personalmente al niño en los casos oportunos, si es necesario en privado, directamente o por mediación de otras personas u organismos, de una forma apropiada a su discernimiento, a menos que ello sea manifiestamente contrario a los intereses superiores del niño;

- permitir al niño expresar su opinión;

c. tener debidamente en cuenta la opinión expresada por el niño. 
Derechos del Niño de la ONU7, cuya Observación General no 12, de julio de 2009, dedicada monográficamente a la audiencia al menor, dice:

El derecho a ser escuchado forma parte del núcleo fundamental de la Convención, junto con el derecho a la vida, a la no discriminación y el derecho a que el interés superior del menor sea una consideración primordial. Además de ello, el derecho del niño a ser escuchado y a que sus opiniones se tomen en serio debe también entenderse como un principio esencial para la determinación el mejor interés del niño, considerado un interés superior.

Desde esta orientación, que como hemos dejado expuesto ha estado presente $a b$ initio en el derecho a ser oído recogido en el art. 12 CDN, alcanza pleno significado el inciso y que su opinión sea tenida en cuenta. Como puso de relieve el Informe del Defensor del Pueblo de 2014, que valoró la incorporación al ordenamiento español del derecho a la escucha del menor: "El concepto de escucha en el marco de la Convención es más exigente, ya que además de atender a lo escuchado ha de razonarse la decisión de apartarse de lo manifestado por el niño" ${ }^{8}$. Por todo ello, en 2015 se añade al derecho a ser oído recogido en el art. 9 LOPM el inciso y escuchado, además de completar y desarrollar la redacción inicial del derecho9.

${ }^{7}$ Dicho Comité se crea en el art. 43 de la CDN con la finalidad de examinar los progresos de cada uno de los países en el cumplimiento de dicho instrumento. En esa tarea, además del seguimiento de los informes nacionales, cobran gran relevancia como doctrina autorizada del Comité las denominadas "Observaciones generales", a través de las cuales aborda de manera sistemática diversos aspectos relacionados con la interpretación de la Convención, así como la protección y promoción de los derechos de los niños en todo el mundo. El Comité ha publicado hasta la fecha diecisiete de estas Observaciones.

8 El Informe del Defensor del Pueblo de 2014 sobre la escucha y el interés del menor, elaborado tras la Observación General no 12 del Comité de los Derechos del Niño de la ONU, analiza cómo se está haciendo en España la participación y la escucha de los niños en la toma de decisiones que les afectan con vistas a garantizar su superior interés. Además de esa función evaluadora, aporta propuestas prospectivas, sobre los requisitos básicos que deben cumplir los métodos adoptados para que se tengan debidamente en cuenta las opiniones de los niños en todos los asuntos que los afecten. Puede consultarse en:https://www.defensordelpueblo.es/wpcontent/uploads/2015/05/2014-05-Estudio-sobre-la-escucha-y-el-interes-superior-del-menor.pdf.

${ }^{9}$ Artículo 9 LOPM. Derecho a ser oído y escuchado.

1. El menor tiene derecho a ser oído y escuchado sin discriminación alguna por edad, discapacidad o cualquier otra circunstancia, tanto en el ámbito familiar como en cualquier procedimiento administrativo, judicial o de mediación en que esté afectado y que conduzca a una decisión que incida en su esfera personal, familiar o social, teniéndose debidamente en cuenta sus opiniones, en función de su edad y madurez. Para ello, el menor deberá recibir la información que le permita el ejercicio de este derecho en un lenguaje comprensible, en formatos accesibles y adaptados a sus circunstancias.

En los procedimientos judiciales o administrativos, las comparecencias o audiencias del menor tendrán carácter preferente, y se realizarán de forma adecuada a su situación y desarrollo evolutivo, con la asistencia, si fuera necesario, de profesionales cualificados o expertos, cuidando preservar su intimidad y utilizando un lenguaje que sea comprensible para él, en formatos accesibles y adaptados a sus circunstancias informándole tanto de lo que se le pregunta como de las consecuencias de su opinión, con pleno respeto a todas las garantías del procedimiento.

2. Se garantizará que el menor, cuando tenga suficiente madurez, pueda ejercitar este derecho por sí mismo o a través de la persona que designe para que le represente. La madurez habrá de valorarse por personal especializado, teniendo en cuenta tanto el desarrollo evolutivo del menor como su capacidad para comprender y evaluar el asunto concreto a tratar en cada caso. Se considera, en todo caso, que tiene suficiente madurez cuando tenga doce años cumplidos. 
Tras esta reforma, el vínculo instrumental entre la audiencia al menor y la determinación de su interés se explicita, al incorporarse al art. 2.2 b) LOPM criterios (no taxativos) para su determinación. El segundo de los enunciados es "la consideración de los deseos, sentimientos y opiniones del menor, así como su derecho a participar progresivamente, en función de su edad, madurez, desarrollo y evolución personal, en el proceso de determinación de su interés superior". Así pues, resulta manifiestamente claro que la audiencia del menor se inscribe en la actual consideración del menor como un sujeto activo, dotado de una capacidad natural progresiva y creciente, que participa en la toma de las decisiones que le atañen, y cuya personalidad ha de tenerse en cuenta para la determinación de su interés. Representa así un signo indicativo de la tendencia actual del Derecho, que supera las actitudes paternalistas hacia el menor y potencia la formación y expresión de su personalidad ${ }^{10}$.

Además de esta general previsión del art. 9 LOPM, el derecho del menor a ser oído se recoge en nuestro Derecho en preceptos concretos que lo explicitan para supuestos determinados y con redacciones diversas, fruto de la dispar cronología de las normas.

En este sentido pueden citarse los siguientes preceptos del Código civil:

a) Art. 92.2 Cc.: en sede de efectos comunes a la nulidad, separación o divorcio, el juez "ha de velar por el cumplimiento" del derecho de los hijos menores a ser oídos en los procedimientos sobre su custodia, cuidado y educación.

b) Art. 92.6 Cc.: en la misma sede, y antes de decidir el régimen de guarda, el juez debe oír a los hijos menores que tengan suficiente juicio si lo estima necesario de oficio, o a petición del Fiscal, partes, miembros del equipo técnico judicial, o del propio menor.

c) Art. 159 Cc.: cuando los padres viven separados, y a falta de acuerdo, el juez "oirá" a los hijos menores "que tuvieran suficiente juicio y, en todo caso, a los que fueran mayores de doce años", antes de decidir al cuidado de qué progenitor quedan.

d) Art. 154.3 Cc.: en el ejercicio de la patria potestad, los padres deben oir a los hijos que tengan suficiente madurez, antes de adoptar decisiones que les afecten.

e) art. 177.3.3 Cc.: en el procedimiento de adopción, ha de oírse al adoptando menor de doce años "de acuerdo con su edad y madurez", mientras que el mayor

Para garantizar que el menor pueda ejercitar este derecho por sí mismo será asistido, en su caso, por intérpretes. El menor podrá expresar su opinión verbalmente o a través de formas no verbales de comunicación.

No obstante, cuando ello no sea posible o no convenga al interés del menor se podrá conocer la opinión del menor por medio de sus representantes legales, siempre que no tengan intereses contrapuestos a los suyos, o a través de otras personas que, por su profesión o relación de especial confianza con él, puedan transmitirla objetivamente.

3. Siempre que en vía administrativa o judicial se deniegue la comparecencia o audiencia de los menores directamente o por medio de persona que le represente, la resolución será motivada en el interés superior del menor y comunicada al Ministerio Fiscal, al menor y, en su caso, a su representante, indicando explícitamente los recursos existentes contra tal decisión. En las resoluciones sobre el fondo habrá de hacerse constar, en su caso, el resultado de la audiencia al menor, así como su valoración.

10 En este sentido, vid. Vila RAMOS, B., "La posición del menor en el ordenamiento y el ejercicio de sus derechos fundamentales. Especial referencia a los supuestos conflictivos en el ámbito del Derecho de familia”, R.C.D.I., no 767, p. 1345. 
de dicha edad ha de consentir la adopción (art. 177.1. Cc.). En cambio para el acogimiento, no sólo se requiere el consentimiento del mayor de doce años, sino también del menor que "tuviera suficiente madurez" (art. 173.2 Cc.). La ausencia de referencia alguna del Código a la audiencia del menor se explica porque el procedimiento para la constitución del acogimiento es objeto de regulación en la legislación autonómica.

f) art. 231 Cc: la constitución de la tutela requiere la previa audiencia judicial del tutelado "si tuviera suficiente juicio y siempre si fuera mayor de doce años".

Y en la Ley de Enjuiciamiento Civil:

a) Art. 770.4 LEC: en los procedimientos de nulidad, y en los contenciosos de separación o divorcio, se oirá a los hijos menores o incapacitados "si tuviesen suficiente juicio y, en todo caso, a los mayores de doce años", cuando "se estime necesario de oficio o a petición del fiscal, partes o miembros del equipo técnico judicial o del propio menor".

b) Para los procesos de separación o divorcio de mutuo acuerdo, el art. 777.5 LEC establece una previsión semejante, en cuya virtud, tras la ratificación de la demanda por ambos cónyuges y si hay hijos menores o incapacitados, el tribunal recabará informe del Ministerio Fiscal sobre las medidas del convenio en relación con ellos, y los oirá si tuvieran suficiente juicio cuando se estime necesario de oficio o a petición del MF, partes, miembros del ETJ o del propio menor.

c) El art. 778 bis 4 LEC contempla la audiencia del menor como requisito previo para que juez otorgue o ratifique la autorización para ingresar a un menor en centros de protección específicos para menores con problemas de conducta, conforme a lo previsto también en el art. 26.3 LOPM.

d) En sede de restitución o retorno de menores en supuestos de sustracción internacional, el art. 778.8 quinquies exige que antes de adoptar cualquier decisión el juez oiga al menor, "a menos que no se considere conveniente atendiendo a la edad o grado de madurez del mismo, lo que habrá de hacerse constar en resolución motivada".

e) El art. 780.1.3 LEC, tras su reforma por Ley 15/2015, de 28 de julio, contempla el derecho del menor a ser parte y a ser oído en el proceso de oposición a medidas administrativas de protección de menores.

Además, y dada la importancia de la norma, ha de destacarse la Ley de Autonomía del Paciente, cuyo art. 9.3 c) recoge el derecho del menor a ser escuchado y a que su opinión sea tenida en cuenta cuando no puede prestar el consentimiento informado por falta de capacidad intelectual y emocional para conocer el alcance de la intervención, y se presta entonces por representación.

En conclusión, la lectura de las normas expuestas demuestra cómo, a nivel internacional y nacional, la audiencia al menor se configura como un verdadero derecho, a proteger y garantizar en cualquier ámbito de decisión (privado o público, judicial o 
administrativo) que le afecte. Derecho que dentro del proceso es manifestación concreta del derecho a la tutela judicial efectiva de los intereses del menor ${ }^{11}$, y fuera de él se configura como una obligación, tanto de los poderes públicos como de quien ejerza potestades privadas, de respetar la personalidad y creciente autonomía del menor. La diferente redacción de las normas se explica por el progresivo perfeccionamiento que el paso del tiempo ha comportado en la configuración y entendimiento de dicho derecho, pero debe superarse con una interpretación integradora que facilite y unifique su aplicación en cualquier ámbito. Para ello, el carácter general y más moderno del art. 9 LOPM lo erige necesariamente en piedra del toque del sistema, a partir del cual procurar la global participación del menor que persigue. De manera que, aun no prevista por la normativa concreta reguladora de la decisión a adoptar, ha de garantizarse siempre el derecho de audiencia del menor en las condiciones descritas en dicho precepto, cuyas lagunas pueden completarse con otros. Así, por ejemplo, no hay norma en el Código civil ni en la LEC que exija la audiencia del menor en el procedimiento de medidas previas ni en las provisionales, lo que no puede aducirse para negar su procedencia, dada la general previsión del art. 9 LOPM12. En el otro sentido, el art. 778.8.2 quinquies LEC contempla la posibilidad de que la audiencia del menor se practique a través de videoconferencia, lo cual podría extenderse a otros supuestos distintos a este procedimiento de restitución de menores en caso de sustracción internacional.

Especialmente, la nueva redacción del art. 9 LOPM supera la interpretación que parte de la doctrina ${ }^{13}$ había defendido, considerando que su regla general se limitaba a otorgar al menor un derecho a exigir la audiencia, que el juez podría denegar motivadamente en el interés del menor ${ }^{14}$. A esta limitada eficacia de la regla general, esta interpretación oponía la reforzada que comportarían los supuestos legales de previsión expresa de la audiencia, donde ésta sí sería vinculante en los términos previstos en cada uno de tales preceptos. Hoy no cabe defender tal interpretación. Con independencia de que se halle o no recogido en textos expresos relativos a resoluciones que afecten al menor, los responsables de adoptarlas tienen el deber de respetar este derecho y, en caso contrario, la resolución será nula por vulnerar los derechos del menor ${ }^{15}$.

${ }^{11}$ Así, por ejemplo, STC 99/2019, de 18 de julio: "Es abundante el acervo doctrinal (por todas, STC 183/2008, de 22 de diciembre, FJ 5) que afirma, como "parte del contenido esencial del art. 24.1 CE», el derecho de cualquier menor, con capacidad y madurez suficiente, a ser oído en vía judicial en la adopción de medidas que afectan a su esfera personal".

$12 \mathrm{Y}$, de hecho, así viene entendiéndolo la jurisprudencia.

${ }^{13}$ Así, MarTínez de Aguirre AldaZ, que cita en el mismo sentido a Gullón Ballesteros: vid. MartínEZ de Aguirre Aldaz, C., en De Pablo Contreras, P., (coord..), Curso de Derecho Civil, tomo I, vol. II, 6a ed., Madrid, Edisofer, 2018, pp. $122 \mathrm{~s}$.

14 Esta interpretación se fundaba en el tenor literal de la redacción original del art. 9.3 LOPM: "3. Cuando el menor solicite ser oído directamente o por medio de persona que le represente, la denegación de la audiencia será motivada y comunicada al Ministerio Fiscal y a aquéllos".

$15 \mathrm{El}$ art. 211-6.2 CcCat., bajo el título "Interés superior del menor", recoge una acertada, breve y clara regla general con expresa alusión a la esfera patrimonial, que se echa de menos en el extenso art. 9 LOPM: "El menor de edad, de acuerdo con su edad y capacidad natural y, en todo caso, si ha cumplido doce años, tiene derecho a ser informado y escuchado antes de que se tome una decisión que afecte directamente a su esfera personal o patrimonial". Su destinatario no son sólo los poderes públicos, sino también los titulares de potestades privadas. 


\section{Presupuestos para el ejercicio del derecho a ser oído: el doble test de conveniencia y madurez}

A partir de su configuración legal, doctrina y jurisprudencia coinciden en que el derecho de audiencia del menor no tiene carácter absoluto, sino que se somete a un doble test, de conveniencia o necesidad, y de madurez ${ }^{16}$. El primero corresponde al juez, y permite eludir la audiencia en resolución motivada en el interés del menor. Así resulta del art. 9.3 LOPM y de la mayoría de los preceptos mencionados, y es coherente con los textos internacionales, como el art. 14 de la Carta Europea de los Derechos del Niño ${ }^{17}$.

El mencionado Informe de la Defensora del Pueblo de 2014 se mostró crítico a este respecto, imputando a la legislación española concebir la escucha del menor no como un derecho, sino como una facultad judicial sujeta al principio de oportunidad. A mi entender, la nueva redacción dada al art. 9 LOPM responde a esta crítica, y deja claro que la negativa a la audiencia ha de ser excepcional y fundada en la garantía de los derechos del menor. Y no una atribución al juez de la facultad de no escuchar.

En segundo lugar, y también en todos los textos mencionados, el derecho de audiencia del menor se liga a dos parámetros: la suficiente madurez del menor y la edad. Que determinan y modulan tanto la necesidad de dar audiencia o no al menor, como la de tener en cuenta sus opiniones. En cuanto a la suficiente madurez del menor, el art. 9.2 LOPM especifica que habrá de ser valorada por personal especializado "teniendo en cuenta tanto el desarrollo evolutivo del menor como su capacidad para comprender y evaluar el asunto concreto a tratar en cada caso". Y la edad introduce un criterio objetivo, que determina una presunción general de madurez en los menores que hayan cumplido doce años (art. 9.2.1 i.f. LOPM).

Las Observaciones del Comité de los Derechos del niño de la ONU recomiendan no establecer hitos objetivos para el ejercicio de este derecho, sino atender en cada caso a la madurez del menor. Con la recepción de este criterio mixto, entiendo que nuestro Derecho se muestra especialmente respetuoso con estas Observaciones, al posibilitar por debajo de doce años atender a la madurez personal de cada menor, y presumirla a partir del cumplimiento de dicha edad.

Ha de advertirse que, en la práctica de los juzgados, el equipo sicosocial asignado suele constar de un sicólogo y un trabajador social, cuyos informes pueden alcanzar en el proceso una trascendencia enorme. Aunque la LOPM establece que la madurez se valore por personal especializado, hay voces que defienden la conveniencia de que sea el juez quien

\footnotetext{
16 En este sentido, la STEDH 72\2016, de 11 de octubre (Caso Iglesias Casarrubios y Cantalapiedra Iglesias contra España) declara: "El Tribunal, en cuanto a la audición de las menores por un Tribunal, estimó que sería ir muy lejos decir que los tribunales internos están siempre obligados a oír a un menor en la vista cuando está en juego el derecho de visitas de un progenitor que no ejerce la custodia. En efecto, esto depende de las circunstancias particulares de cada caso y teniendo debidamente en cuenta la edad y la madurez del menor en cuestión (Sahin contra Alemania (JUR 2003, 162884) [GS], núm.30943/1996, ap. 73, TEDH 2003-VIII)”. En la doctrina, dicha afirmación es unánime: por todos, Rivero HERNÁNDEZ, F.: "El derecho del menor a ser oído no es absoluto, porque puede ser denegado, precisamente en su propio interés, cuando no se revele nada útil de dicha audiencia, antes bien, pueda resultarle perjudicial", El interés del menor, 2ª ed., Madrid, Dykinson, 2007.
}

17 Ciertamente, no de forma expresa el art. 12 CDN, pero la necesaria fundamentación de la negativa en el interés del menor viene amparada por el art. $3 \mathrm{CDN}$. 
realice tal valoración ${ }^{18}$. Que habrá de partir de una idea básica: el fomento y la protección de la personalidad progresiva del menor y el reconocimiento de sus derechos traen como corolario ineludible la afirmación de que es conforme al interés del menor cuanto favorezca el ejercicio de los mismos. Dado que la audiencia es precisamente ejercicio de un derecho, de intervención en la decisión que le atañe, ha de estarse por escuchar al menor, y sólo excepcionalmente, por lo contrario. Por ende, excluir la audiencia del menor por falta de madurez sólo tiene sentido en edades muy tempranas.

\section{Modo de ejercer el derecho de audiencia}

El menor puede exponer su opinión bien personalmente, bien a través del representante que designe. En el primer caso, la audiencia habrá de tener carácter preferente en los procedimientos judiciales, y se realizará "de forma adecuada a su situación y desarrollo evolutivo, con la asistencia, si fuera necesario, de profesionales cualificados o expertos", preservando la intimidad del menor, en formatos accesibles para él (art. 9.1.2. LOPM), "en condiciones idóneas para la salvaguarda de sus intereses" y sin interferencias de otras personas (art. 770.4 LEC).

Además, ha de brindarse al menor la información suficiente, en formatos accesibles y adaptados a sus circunstancias, sobre la cuestión a decidir, así como las consecuencias de su opinión ${ }^{19}$.

Ahora bien, adviértase que ambos temas son muy delicados. En conflictos familiares, y señaladamente ante crisis de los padres, los especialistas no consideran beneficioso que el menor esté al tanto de todos los detalles procesales del litigio que les enfrenta. Antes, bien: la información debe ser adecuada (sólo de lo que para los menores es relevante), neutral y positiva, para proteger al menor en detalles perjudiciales. Y en cuanto al conocimiento de las consecuencias, los expertos señalan que debe evitarse responsabilizar al menor del efecto de sus manifestaciones, a riesgo de coartar su expresión. Teniendo en cuenta, por supuesto, que el menor puede negarse a declarar, o incluso a comparecer: estamos ante un derecho y no ante una obligación del menor ${ }^{20}$.

Como postura intermedia, puede designar un representante que exponga su opinión, lo cual presupone su suficiente madurez para tal designación. Y subsidiariamente, cuando ni la audiencia personal ni por representante sean posibles o no convengan al interés del menor, o éste se niegue a ambas, puede conocerse su opinión a través de sus representantes legales, siempre que no tengan intereses contrapuestos. Ello excluye esta opción en los pleitos sobre crisis matrimoniales, custodia, visitas, alimentos, protección del menor o administración de sus bienes, entre otros. También a través de "otras personas que, por su profesión o relación de especial confianza con el menor, puedan transmitirla (su

\footnotetext{
18 Entre otros autores, en tal sentido ANDREu MARTínez, M. B., La autonomía del menor en la asistencia sanitaria y el acceso a su historia clínica, Cizur Menor, Aranzadi-Thomson Reuters, 2018, p. 40.

19 Observación General número 12 del Comité de los derechos de niño: "las medidas a adoptar para garantizar el derecho a ser escuchado deben incluir los mecanismos necesarios para darles información, garantizar su audiencia, con el apoyo que requiera, evaluar la capacidad del niño y comunicarle los resultados de la audiencia".

${ }^{20}$ En este sentido, vid. §16 de la Observación General no 12 del Comité de los Derechos del Niño.
} 
opinión) objetivamente". De manera que estas personas no deben manifestar su propio parecer sobre lo más beneficioso para el menor, sino lo que él piensa, siente o dice.

El art. 18 LJV establece una serie de completas previsiones acerca de cómo debe ser la comparecencia en el procedimiento-tipo de jurisdicción voluntaria, cuando el expediente afecte a menores. Prevé:

a) Que se celebre ante el juez o el letrado de la Administración de Justicia, según en quien recaiga la competencia para resolver el expediente.

b) Que pueda celebrarse no en el mismo acto de la comparecencia, regida por las normas de la vista del juicio verbal de la LEC, sino en acto separado, "sin interferencias de otras personas" 21.

c) Que pueda asistir el Ministerio Fiscal. Sin embargo, su presencia debe ser obligatoria. Así, la STC 17/2006 de 30 enero, consideró que la negativa de la Sala a permitir la intervención del Ministerio Fiscal en la diligencia de exploración de dos menores para conocer su opinión sobre la conveniencia de atribuir su guarda y custodia a uno u otro de los progenitores, genera indefensión que afecta al interés público y al interés prevalente de las menores.

d) Que se oiga a los menores en "condiciones idóneas, en términos que les sean accesibles, comprensibles y adaptados a su edad, madurez y circunstancias, recabando el auxilio de especialistas cuando ello fuera necesario".

e) Que del resultado de la exploración "se extienda acta detallada y, siempre que sea posible, sea grabada en soporte audiovisual". Si tuviera lugar después de la comparecencia, se dará traslado del acta a los interesados para que puedan efectuar alegaciones en el plazo de cinco días. Lo cual tiene sentido porque, si se celebra antes de la comparecencia, o con ocasión de ella, pueden los interesados formular oralmente sus conclusiones. La comparecencia también se graba, conforme a la LEC.

Pues bien, esta última previsión de la LJV motivó el planteamiento de una cuestión de inconstitucionalidad por un Juzgado de Primera Instancia de Barcelona, por la posible vulneración del derecho a la intimidad del menor. El proponente se planteaba si la documentación total de la audiencia al menor prevista en el art. 18.2.4르 LJV podía vulnerar dicho derecho a la intimidad y dejarle expuesto a las represalias de las partes, especialmente grave en conflictos entre sus padres. La reciente STC 64/2019, de 9 de mayo, ha desestimado dicha cuestión, confirmando la constitucionalidad del párrafo enjuiciado de la LJV.

En ella, el Tribunal Constitucional observa que ante la colisión de derechos fundamentales entre el derecho del menor a la intimidad y el de tutela judicial efectiva de sus padres, se impone un juicio de proporcionalidad sobre la norma, para comprobar si cumple la triple condición de: idoneidad, o adecuación de la medida al fin propuesto; necesidad para alcanzar su objetivo, sin que su logro sea posible con otra más moderada; $y$ proporcionalidad en sentido estricto, en cuanto de ella se derivan más beneficios que perjuicios. Tras argumentación detenida, considera que la norma enjuiciada cumple todos

${ }^{21}$ Lo cual responde al párrafo 43 de la Observación General no 12 del Comité de los Derechos del Niño, que recomienda su práctica bajo condiciones de confidencialidad y no como audiencia pública. 
los cánones y pondera adecuadamente otros intereses en conflicto, como es el de los padres, "que aun siendo de menor rango que el del menor, no resulta por ello desdeñable". El conocimiento por las partes del resultado de la audiencia del menor es consecuencia del principio de contradicción que rige el proceso, si bien observa que el momento crucial para garantizar los derechos de audiencia y a la intimidad del menor no se sitúa en el traslado del acta, "sino en el desarrollo de la audiencia judicial, donde el juez o secretario deben velar porque el menor circunscriba sus manifestaciones a las necesarias para averiguar los hechos y circunstancias controvertidos, de modo que la exploración sólo verse sobre las cuestiones estrictamente relacionadas con el objeto del expediente". Así acotado el desarrollo de la exploración judicial, "el acta ha de ser puesta en conocimiento de las partes para que puedan efectuar sus alegaciones". Y aunque el TC no haya expresado nada en cuanto a la grabación, ha de entenderse que procede idéntica conclusión, teniendo en cuenta además su conveniencia para evitar la reiteración innecesaria de exploraciones al menor.

Por consiguiente, esta sentencia viene a excluir que el acta extendida tras la audiencia al menor sólo refleje la fecha, hora, lugar y personas presentes en la misma, o seleccione entre lo manifestado y sólo incorpore lo que no comprometa la intimidad del menor, así como que el juez se limite a trasladar oralmente el contenido de la exploración ${ }^{22}$. Y también exige la entrega del acta a las partes, frente a resoluciones judiciales que habían entendido que su destinatario es el tribunal ${ }^{23}$.

Por lo demás, entiendo que cuanto declara el Tribunal Constitucional no sólo es aplicable a los expedientes de jurisdicción voluntaria, sino también a todos los procesos en que haya de escucharse a los menores, pese a la inexistencia de norma concreta sobre la documentación de la audiencia en la LEC o en la LOPJ. Como ya he dejado expuesto, considero necesaria una interpretación integradora de las normas que de forma dispersa desarrollan el derecho de audiencia del menor. Y, por otra parte, el derecho del menor a la información exige que el juez le traslade antes de su práctica que cuanto declare constará en un acta, que va a trasladarse a sus padres, y que tiene derecho a reservarse su opinión.

\section{Eficacia del derecho de audiencia del menor}

Puede abordarse desde una perspectiva negativa, para identificar la sanción procedente a su inobservancia, y desde otra positiva, que determine la trascendencia a otorgar a la opinión del menor.

22 La falta de concreción legal hasta el momento ha propiciado que la práctica judicial sobre la documentación de la audiencia al menor haya sido muy dispar. Sin que falten resoluciones que hayan decretado nulidad de actuaciones por no constar en autos el resultado de la exploración del menor. Es el caso de la SAP Navarra 20 diciembre 2001, con fundamento dicha falta de reflejo impide enjuiciar en la segunda instancia cómo se ha valorado. Tiene interés destacar que en este caso, la falta de constancia respondió a la petición de la menor, que así solicitó en su audiencia al juez de primera instancia.

23 A este respecto, vid. las resoluciones judiciales y opiniones expuestas por ABEL LuCH, X., "La confidencialidad de la audiencia del menor", Diario La Ley, § 6414/2019, p. 3. 


\section{V.1. Sanción a la inobservancia del derecho de audiencia}

El Tribunal Constitucional ha declarado reiteradamente que la falta de audiencia de los menores "que estén en condiciones de formarse un juicio propio", con la correspondiente adopción de medidas en procesos judiciales sin su audiencia, constituye vulneración de su derecho a la tutela judicial efectiva. En este sentido se manifiestan, entre otras, las SSTC 221/2002, de 25 de noviembre; 21/2004, de 19 abril; 152/2005, de 6 de junio; 17/2006, de 30 de enero y 138/2008, de 22 diciembre.

Tiene interés destacar que la STC 152/2005, de 6 junio, estima vulnerado el derecho a la tutela judicial efectiva de un menor a quien sólo se oyó para la fijación de las medidas provisionales, pero no para las definitivas, ni tampoco antes de dictarse la sentencia de apelación, momento en que contaba con nueve años. El Tribunal considera que para alterar el régimen previsto en la sentencia de instancia, la Audiencia debería haber abierto un trámite específico para oír al menor, y también a su hermana pequeña, a quien no se había oído por falta de madurez, pero que al dictado de la segunda sentencia contaba ya con madurez suficiente. Por consiguiente, el Tribunal Constitucional subraya la exigencia de escuchar al menor cuantas veces vayan a adoptarse, a lo largo de un proceso, medidas que le afecten, en primera instancia y en apelación. De manera que es una práctica indeseable considerar innecesaria la audiencia del menor en un momento procesal ulterior, porque conste en los autos un informe del equipo técnico judicial realizado tiempo atrás.

En la misma línea se pronuncia la STEDH 72/2016, de 11 de octubre (Caso Iglesias Casarrubios y Cantalapiedra Iglesias contra España), que condena a España por vulneración del derecho de la demandante a un juicio justo. En este caso, la madre de dos hijas había solicitado la audiencia de las menores en el procedimiento de divorcio contencioso, para la fijación del régimen de custodia. El juez la deniega, sin motivación bastante a juicio del TEDH, y basa su decisión para la concesión de la guarda y custodia en las opiniones expresadas por la hija mayor ante el equipo psicosocial, y por la menor en los informes periciales, en ambos casos elaborados con ocasión del previo proceso de separación.

No obstante, la STC 22/2008, de 31 enero, declara que esta doctrina sobre la indefensión por la falta de audiencia en el momento de la adopción de las medidas provisionales o en cualesquiera de las fases del procedimiento de adopción de medidas paterno filiales, no puede proyectarse sin más, con idéntica trascendencia constitucional, a los autos que contemplan su ejecución provisional y la determinación de si existe causa legal en que pueda fundarse la oposición a dicha ejecución. Y concluye que no concurre indefensión por no haberse escuchado a la menor en dicha fase ejecutiva. Lo cual resulta lógico, dado que en ejecución no se decide, sino que se hace efectivo lo ya decidido.

En el mismo sentido se ha pronunciado el Tribunal Supremo, de forma ininterrumpida y unánime, matizando además reiteradamente que no hay motivo de nulidad alguno si la negativa judicial a la práctica de la audiencia del menor se funda y argumenta sobre su interés, protección o falta de juicio suficiente. En la jurisprudencia más reciente ha de mencionarse la STS 25 octubre 2017 (RJ 4676); la muy concienzuda, con numeroso aporte de jurisprudencia previa, STS 15 enero 2018 (RJ 28) ${ }^{24}$; y el ATS 12

\footnotetext{
${ }^{24}$ Esta sentencia resuelve en un caso de visitas de los abuelos, en el que se estima necesaria la audiencia de los menores. Reitera su criterio la STS 6 abril 2018, considerando que es lícito estar a la exploración llevada a
} 
diciembre 2018 (RJ 5454), que con cita de la sentencia anterior inadmite el recurso por falta de interés casacional.

Esta jurisprudencia declara reiteradamente que nos hallamos ante un derecho del menor que no puede ser renunciado por las partes, cuyo cumplimiento compete tutelar al juez de oficio, si ninguna de las partes, el MF o el propio menor lo ha instado previamente. Así se pronuncian, entre otras, las SSTS 20 octubre de 201425 y 7 marzo 201726. Por consiguiente, el derecho de audiencia del menor es una norma de orden público, indisponible por las partes, y cuyo cumplimiento compete a todos los poderes públicos ${ }^{27}$.

Por consiguiente, la falta de exploración o audiencia al menor, cuando no se haya fundado suficientemente su improcedencia o la falta de madurez del menor, acarrea la nulidad de actuaciones, que puede ser declarada de oficio.

\section{V.2. La opinión del menor y la determinación de su interés}

El art. 9.3 LOPM in fine exige que en las resoluciones sobre el fondo se haga constar, además del resultado de la audiencia del menor, su valoración. De modo que el juez habrá de constatar cuál ha sido la opinión del menor y cómo ha sido tenida en cuenta para tomar la decisión final. Obviamente, la opinión del menor no es vinculante para el juez ni para ninguna otra instancia de decisión. Pero el carácter finalista de la audiencia, dirigida a identificar la situación del menor, cómo vive, siente y piensa sobre el conflicto que le atañe, la liga necesariamente a la determinación del interés superior del menor, que ha de regir la decisión que le afecte. Y, lógicamente, si ésta se aleja de las opiniones, criterios o preferencias manifestadas por el menor, habrá de motivarse detenidamente por qué se entiende que el interés del menor es diferente a sus manifestaciones, o a la postura que ha sostenido. La aproximación general o abstracta a esta cuestión es complicada, pero necesaria, y requiere huir de apriorismos.

Como punto de partida, no debe olvidarse que una consecuencia de cuanto llevamos expuesto, y de la configuración de la audiencia del menor como una manifestación del derecho fundamental a la tutela judicial efectiva, es que su resultado no es un medio de prueba. El menor no declara sobre hechos, no comparece como testigo, ni el juez practica sobre él un reconocimiento conforme al art. 355 LEC. De manera que el juez no puede

cabo por un experto cuando por la edad del menor no es aconsejable una exploración judicial de éste. La STS 1 marzo 2019 cita esta doctrina considerando correcto que en la SAP se hubieran tenido en cuenta las manifestaciones de la menor de seis años, hechas ante un sicólogo y reflejadas en el correspondiente informe.

25 STS 20 octubre 2014: "La aparente contradicción entre el Código Civil y la Ley de Enjuiciamiento Civil, viene a ser aclarada por la Ley del Menor y por el Convenio sobre Derechos del Niño, en el sentido de que cuando la edad y madurez del menor hagan presumir que tiene suficiente juicio y, en todo caso, los mayores de 12 años, habrán de ser oídos en los procedimientos judiciales en los que se resuelva sobre su guarda y custodia, sin que la parte pueda renunciar a la proposición de dicha prueba, debiendo acordarla, en su caso, el juez de oficio. En este mismo sentido la sentencia del Tribunal Constitucional de 6 de junio de 2005". Y también: "para que el juez o tribunal pueda decidir no practicar la audición, en aras al interés del menor, será preciso que lo resuelva de forma motivada".

${ }^{26}$ STS 7 marzo 2017: "En relación a la falta de exploración de la hija, esta sala se ha pronunciado con reiteración respecto a la necesidad de ser oído el menor en los procedimientos que directamente les afectan".

27 En palabras de la STC 64/2019, de 9 de mayo: "este derecho forma parte del estatuto jurídico indisponible de los menores, como norma de orden público, de inexcusable observancia para todos los poderes públicos (y así también STC 141/2000, de 29 mayo). De ahí que su no observancia vulnere el art. 24.1 CE del menor". 
argumentar la negativa a la audiencia como si fuera una prueba, negando su práctica sólo por entenderla innecesaria para el esclarecimiento de los hechos relevantes para el pleito. Como ya ha quedado expuesto, la negativa debe basarse en el interés del menor: bien porque se estime innecesario escucharle porque la decisión a tomar no afecte al mismo, bien porque se aprecie la existencia de un riesgo o peligro en la audiencia que contraríe dicho interés ${ }^{28}$.

Así pues, la escucha al menor, y la toma en consideración de cuanto expone, se dirige a la identificación de su interés en el asunto debatido. Y si es un apriorismo indeseable identificar interés con opinión del menor, también lo es contraponer interés con voluntad o deseo del menor, atribuyendo a éstos últimos una ligereza subjetiva del que carecería el primero. La opinión del menor, su percepción de cuanto le rodea, y lo que el comportamiento de sus referentes le hace sentir, estará fundada en su propia lógica, en muchas ocasiones insobornable ${ }^{29}$. En este sentido, puede arrojar alguna luz acudir a las aportaciones que organismos internacionales y nacionales, doctrina y jurisprudencia han realizado en la última década para tratar de objetivar el interés del menor y excluir su alegación como un cheque en blanco de difícil control. Así, es relevante destacar cómo la Observación General del Comité de los Derechos del Niño de la ONU no 14, de mayo de 2013, sobre el derecho del niño a que su interés superior sea una consideración primordial, recoge en su parágrafo sexto la necesidad de que en las decisiones adoptadas se constate que se ha tenido en cuenta dicho interés, cuáles han sido los criterios para fijarlo y cómo se ha ponderado en relación con otras consideraciones. Esta Observación recomienda elaborar un listado no cerrado de circunstancias a considerar para determinar el interés del niño, que además de ofrecer orientaciones concretas, sea flexible. Y partiendo en todo momento de que el interés superior del niño debe centrarse en primer lugar en lograr el disfrute de todos los derechos comprendidos en la CDN. De manera que esta Observación ha tenido un papel radicalmente importante en la identificación del interés del menor. Y ha propiciado que rija hoy una visión centrada en la defensa del ejercicio de sus derechos, superadora de la más tradicional, que lo venía identificando con la estabilidad emocional e integración social del menor ${ }^{30}$.

Pues bien, para la determinación de dicho interés, el parágrafo 53 de dicha Observación coloca en primer lugar la opinión del niño, señalando especialmente que habrá de tenerse más en cuenta conforme vaya alcanzando mayor grado de madurez, de modo que si la decisión es contraria a dicha opinión, contraría la posibilidad de que el niño participe en la determinación de su interés. Como ya ha quedado expuesto, a ello se adecúa la actual

${ }^{28}$ Así, la STS 15 enero 2018 estima el recurso frente a la sentencia de la Audiencia porque la negativa a la audiencia del menor, como si fuera una prueba, se califica de insuficiente e inadecuada.

${ }^{29}$ Me parecen acertadas, a este respecto, las palabras de RIVERo HERnÁNDEZ: "si lo prevalente es el interés del niño, no puede ignorarse que en más de una ocasión su voluntad razonada y razonable (correctamente interpretada, por tanto) puede ser expresión de unos sentimientos y sensibilidad e indicativos de una personalidad e intereses más valiosos que la propia voluntad per se: es a aquéllos (datos objetivos, sentimientos expresados), y no a ésta (voluntad, mero querer), a los que creo que debe dispensarse particular atención y darles la oportuna relevancia, en especial, a partir de cierta edad", ob. cit., p. 205

30 En este sentido, y sobre la evolución de la jurisprudencia española hacia esta vía de identificación del interés del menor, vid. GuILARTE GuTIÉRREZ, C., La concreción del interés del menor en la jurisprudencia del Tribunal Supremo, Valencia, Tirant lo Blanch, 2014, p. 15. 
redacción del art. 2.2. LOPM, que recoge un listado no exhaustivo de criterios para la determinación del interés superior entre los que ocupa posición preeminente la consideración de sus "deseos, sentimientos, y opiniones".

Todo ello confluye en la exigencia de que la motivación de la decisión adoptada elabore una descripción detenida de cuáles han sido los criterios para identificar el interés del menor, en especial qué papel se ha otorgado a su percepción del conflicto y sus preferencias de resolución, en qué reside en el caso concreto dicho interés y por qué, si es el caso, la decisión adoptada se aparta del criterio manifestado por el menor ${ }^{31}$. Exigencias para la motivación que marcan además el ámbito en que cabe el recurso de casación contra la decisión judicial: no cabe impugnarla si se ha fundamentado de forma que permita seguir el proceso argumentativo seguido por el juez en la búsqueda del interés del menor. Esto es, dado que la casación no es una tercera instancia, no cabe requerir en ella una nueva valoración del interés del menor, salvo que la hecha en instancia sea manifiestamente infundada o irracional ${ }^{32}$

Ilustrativa a este respecto resulta la STS 25 octubre 2012 (RJ 9727), que confirma el criterio de la Audiencia, contrario a modificar el régimen de custodia solicitado por el padre para adecuarlo a la voluntad de los hijos, de dieciséis y diecisiete años, de trasladarse a vivir con él, por entender que la decisión se ha tomado en consideración a su interés. Recuerda el Tribunal Supremo que la revisión en casación: sólo puede realizarse si el juez a quo ha aplicado incorrectamente el principio de protección del interés del menor a la vista de los hechos probados en la sentencia que se recurre ${ }^{33}$.

De manera que, bajo estas condiciones, el juez podrá desatender lo manifestado por el menor: siempre que fundamente razonadamente que la consideración a su interés exige apartarse de sus preferencias. Lo cual ciertamente conduce a admitir, como señala doctrina autorizada, que existe un control último externo, de autoridad, sobre la autonomía del menor, atribuido en algunos casos a los propios padres, en otros al juez o a la

\footnotetext{
${ }^{31}$ A este respecto, la mencionada STC 64/2019, de 9 de mayo, declara: "La reforma de 2015 del art. 9.1 LOPM refuerza la efectividad de dicho derecho, al reflejar que en las resoluciones sobre el fondo en que esté afectado el interés de un menor, debe hacerse constar el resultado de la audiencia y su valoración (último inciso del art. 9.3)".

${ }^{32}$ A diferencia de la decisión de apelación, donde la Audiencia sí puede modificar la valoración del juez sobre la identificación del interés del menor. Por tanto, se cumple en nuestro país la recomendación de la Observación General n 14, del Comité de los Derechos del Niño, recogida en su parágrafo 98, en el sentido de que se permita recurrir las decisiones tomadas cuando se considere que no se ha valorado adecuadamente el interés superior del niño.

33 STS 25 octubre 2012 (RJ 9727): "la Audiencia Provincial ha examinado las pruebas aportadas y ha tenido en cuenta el interés de los menores en un contexto difícil en razón a los conflictos generados sin solución de continuidad por sus progenitores. La consideración de que uno y otro quieren irse con su padre poco tiempo después de que se decidiera asignar a su madre la guarda y custodia, no es ni mucho menos conforme a este interés, antes, al contrario, provoca, o puede provocar, un evidente enfrentamiento con las partes en conflicto. El interés del menor exige un compromiso mayor y una colaboración de sus progenitores tendente a que este tipo de situaciones se resuelvan en un marco de normalidad familiar en la que no todos los deseos del hijo se satisfacen necesariamente mediante el cambio de custodia, a modo de ida y vuelta en razón a su estado de ánimo o de situaciones puntuales de divergencia que modifican a conveniencia del menor la guarda y custodia, propiciando en algún caso situaciones indudablemente perversas para el grupo familiar cuando se involucran otras medidas como la de alimentos o el uso de la vivienda, y ello el Derecho no lo ampara sin más".
} 
administración, que viene a negar esa supuesta capacidad de obrar y autonomía que desde diversos ámbitos se afirma respecto de los menores ${ }^{34}$.

\section{Conclusiones}

1. La Convención de los Derechos del Niño ha impulsado, en sus treinta años de vigencia, una nueva situación jurídica de los menores, caracterizada por su atención como personas activas, sujetos ejercientes de derechos de forma progresiva y creciente de acuerdo con su proceso de madurez. Uno de los derechos básicos es el derecho de audiencia del menor en toda decisión, pública o privada, judicial o extrajudicial, que le afecte. Su finalidad es de carácter instrumental, dado que es expresión del reconocimiento al menor del derecho a participar en la toma de las decisiones que le afecten, para la mejor determinación de su interés.

2. Es obligación inexcusable de todos poderes públicos garantizar este derecho del menor a ser oído y a que su opinión sea tenida en cuenta, y también lo es de los padres, en el ejercicio de sus potestades parentales. Si bien no es un derecho de carácter absoluto, porque su ejercicio se vincula tanto en los textos internacionales como en nuestra legislación a un doble test, de conveniencia y de madurez. En virtud del primero, el juez puede negar legítimamente la audiencia al menor si estima que no es pertinente, por no derivarse de ella ningún beneficio para el menor, o poderle producir un perjuicio. En virtud del segundo, puede obviarse la audiencia del menor si se estima que no cuenta con la madurez suficiente, sólo en caso de que no haya cumplido los doce años. De cualquier manera, en la aplicación de ambos test habrá de partirse de que el interés del menor radica en el ejercicio de sus derechos, de manera que lo excepcional ha de ser la negativa a la práctica de dicha audiencia, y debe fundarse precisamente en el interés del menor.

3. Si la falta de la obligada audiencia al menor comporta la nulidad de actuaciones, en cuanto genera indefensión, el juez no está vinculado por la opinión manifestada por el menor. Podrá apartarse de ella argumentando lógica y razonablemente que, en aplicación de otros criterios objetivos, ha concluido que el interés del menor no se identifica con su voluntad manifestada. Lo que no cabe es oponer, sin más, voluntad e interés del menor, dado que precisamente su voluntad puede estar basada en consideraciones objetivas y razonables atendibles para la toma de la decisión que le concierne.

\footnotetext{
34 En este sentido, Parra Lucán, M. A., en "Minoría de edad", en Tratado de Derecho de la Persona física, Madrid, Civitas-Thomson-Reuters, 2013, p. 588.
} 